\title{
Medication Adherence Amongst Diabetic Patients in a Tertiary Healthcare Institution in Central Nigeria
}

\author{
Fatima lyabo Abdulazeez ${ }^{1}$, Moses Omole ${ }^{2}$ and Sheriff Lekan Ojulari ${ }^{3 *}$ \\ ${ }^{1}$ Department of Clinical Pharmacy and Pharmacy Practice, University of Ilorin, Ilorin, ${ }^{2}$ Department of Clinical Pharmacy and \\ Pharmacy Administration, University of Ibadan, Ibadan, ${ }^{3}$ Department of Physiology, University of Ilorin, Ilorin, Nigeria \\ *For correspondence: Email: ojularis@yahoo.com; Tel: +2348032429067
}

\begin{abstract}
Purpose: To investigate the degree of diabetic patients' compliance with their prescribed medications, factors responsible for non-compliance and how compliance can be enhanced.

Methods: The study involved 220 diabetic patients on anti-diabetic medication (insulin, metformin and gliclazide) visiting the out-patient clinic of the University of Ilorin Teaching Hospital, Nigeria, who met specific criteria. Questionnaires and patient interviews were used to gather information.

Results: A total of 162 patients (73.64 \%) of the patients were non-compliant with medications; 22 of the compliant patients were males while 36 were females. Twenty three of the compliant patients had no formal education unlike the rest. There was significant association $(p<0.05)$ between patients' financial status and compliance. However, there was no significant association $(p>0.05)$ between number of prescribed medications, side effects, patients' level of education, patients' belief of efficacy of medication and compliance.

Conclusion: A very high level of non-compliance to anti-diabetic medication has been observed in the facility studied. Institution of policies that will enhance compliance in these facilities and others in Nigeria is highly recommended.
\end{abstract}

Keywords: Compliance, Adherence, Diabetic, Medication, Prescription

Tropical Journal of Pharmaceutical Research is indexed by Science Citation Index (SciSearch), Scopus, International Pharmaceutical Abstract, Chemical Abstracts, Embase, Index Copernicus, EBSCO, African Index Medicus, JournalSeek, Journal Citation Reports/Science Edition, Directory of Open Access Journals (DOAJ), African Journal Online, Bioline International, Open-J-Gate and Pharmacy Abstracts

\section{INTRODUCTION}

For some decades now, patients' noncompliance with therapeutic regimen has been recognized as a challenge to the successful delivery of healthcare. Drug treatment relies heavily on the cooperation of the patient for selfadministration, as patients' compliance in ambulatory care is an important link between medical process and treatment outcome [1].

Diabetes is a serious condition for an individual and on a global scale. There is rapidly increasing prevalence and as such, patients' compliance with diabetic medication is a great cause for concern [2].

The prevalence of diabetes for all age groups worldwide was estimated to be $2.8 \%$ in 2000 and $4.4 \%$ in 2030 [3]. The total number of people with diabetes is projected to rise from 171 million in 2000 to 366 million in 2030 [3]. The prevalence is higher in men than women [3].

Assisting patients to adhere to often complex treatment regimens and achieve tight blood glucose control is a challenge that must be addressed during all phases of diabetic treatment $[4,5]$. 
The vast majority of diabetic outpatients selfadminister their own medications. Thus, patients' attitude and beliefs can strongly influence the effectiveness of interventions. Patients' perceptions of the importance of glycemic control and their self-care ability have also been identified as factors that may affect patients' compliance $[6,7]$.

This study, therefore, aims to assess lack of compliance with prescribed medications in diabetics, identify factors affecting compliance and seek ways of enhancing patients' compliance.

\section{EXPERIMENTAL}

The research methods used to gather information for this study were mainly questionnaire and patient interviews. The study population includes diabetic patients that visited the outpatient clinic of the endocrine unit of the University of Ilorin Teaching Hospital, Ilorin in central Nigeria over a period of 16 weeks.

\section{Inclusion/exclusion criteria}

The criteria for inclusion in the study were:

1- The patient must have been properly diagnosed as diabetic, that is having a grossly elevated random blood glucose above a specified range (whole blood glucose > 6.7 $\mathrm{mmol} / \mathrm{L}$ or plasma glucose $7.8 \mathrm{mmol} / \mathrm{L}$ ) for a long period of time; or after a formal $75 \mathrm{~g}$ oral glucose tolerance test (OGTT) has been performed, having a venous plasma glucose level $2 \mathrm{~h}$ after loading as $>11.1 \mathrm{mmol} / \mathrm{L}$.

2- Patients must have been on drug treatment for upwards of 6 months. Patients who were newly diagnosed were excluded from this study. 3- Patients on dietary modifications and/or exercise alone were not included

\section{Sample size and sampling technique}

Three hundred (300) patients that visited the clinic over a period of about 16 weeks were initially enrolled in this study out of which 80 did not meet the inclusion criteria. A total of 220 diabetic patients were therefore used in the study. They were selected using random sampling technique and only those who met the inclusion criteria were used. The study design was descriptive.

\section{Procedure}

On each clinic day, patients were randomly selected form the total population of patients that visited. The study and its importance were explained to them and their consent to participate in the study was sought and obtained. Questionnaires were administered to some of them and to a larger number; the questions were read out to them and filled. The patients were also interviewed in order to identify subjective evidence that point to non-compliance but may be difficult to reflect in the questionnaire.

\section{Statistical analysis}

Frequency tables were used to describe and explain the structure differentials of the population used for the study in terms of age, sex distribution, educational level, as well as reasons for intermittent stopping of medications. Chisquare was used to find out the association between (a) number of prescribed medication and compliance with medication regimen, (b) educational qualification and compliance with medication regimen, (c) side effects of medication and compliance with medication regimen, (d) financial status of the patient and compliance with medication regimen, and (e) belief of medication effectiveness and compliance with medication regimen. The level of significance was set at $p<0.05$

\section{RESULTS}

Two hundred and twenty patients were involved in the study. From the results gotten, the number of male was $100(45.45 \%)$ and the female 120 $(54.55 \%)$ (Table 1$)$. The total number of male patients that were found to be compliant with their medications was 22 as compared to the female patients compliant with their medications which was 36 . The number of female and male patients found not to be compliant with their medications were 84 and 78 , respectively. The total number of patients compliant was found to be 58 and those not compliant to be 162 .

The ages of the patients were spread over a wide range showing a greater number of the patients aged between 60-69 years with only about 17 patients aged below the age of 40 years (Table 1). The results show in all the age groups the number of patients that were not compliant with their medications were more, except for patients in the age group less than 40 years, where the number of patients compliant with their medications is more than those not compliant. 
Table 1: Age and sex of distribution of patients

\begin{tabular}{llll}
\hline & $\begin{array}{l}\text { Compliant } \\
\text { patients, } \\
\text { N(\%) }\end{array}$ & $\begin{array}{l}\text { Non- } \\
\text { compliant } \\
\text { patients, } \\
\text { N(\%) }\end{array}$ & Total (\%) \\
\hline Gender & & & \\
Male & $22(37.69)$ & $78(48.15)$ & $100(45.54)$ \\
Female & $36(62.07)$ & $84(51.85)$ & $120(54.55)$ \\
Total & $58(26.39)$ & $162(73.63)$ & $220(100)$ \\
Age & & & \\
(years) & & & $17(7.73)$ \\
$<40$ & $12(5.46)$ & $5(2.27)$ & $46(20.91)$ \\
$40-49$ & $8(3.64)$ & $38(17.27)$ & $52(23.64)$ \\
$50-59$ & $14(6.36)$ & $38(17.27)$ & $82(37.30)$ \\
$60-69$ & $18(8.18)$ & $64(29.09)$ & $22(10.00)$ \\
$>70$ & $6(2.72)$ & $16(7.27)$ & $220(100.00)$ \\
\hline Total & $58(26.36)$ & $162(73.64)$ & \\
\hline
\end{tabular}

A total of 145 of the patients had educational qualification of varying degree with 40 patients having primary education, 59 patients having secondary education and 46 patients having tertiary education. Table 2 shows that majority of those not compliant with their medications have no educational qualification with the non- compliant males falling into this category being $15.45 \%$ and the females $16.67 \%$.

Patients with medium financial status have the greatest number (127 patients), with a correspondingly high number of patients that are not compliant with their medications (89 patients). It can be seen from Table 3 that the number of male patients that are of low financial status that are not compliant with their medications are fewer than the female patients, as compared to with those with medium and high financial status who are more than the females in their respective classes.

The numbers of patients that believe in the effectiveness of their medications (57.73\%) are more than those that do not believe (42.27\%) (Table 4). A high number of female patients believe in the efficacy of their medications (33.64 $\%$ ) while a high number of male patients believe in the non-efficacy $(24.09 \%)$ of their medication. We assessed compliance with drug medication among diabetics visiting the outpatient clinic of the endocrine unit of the University of Ilorin

Table 2: Educational qualifications of diabetic patients

\begin{tabular}{lcccccc}
\hline $\begin{array}{l}\text { Educational } \\
\text { qualification (\%) }\end{array}$ & $\begin{array}{c}\text { Compliant } \\
\text { male } \\
\text { patients N(\%) }\end{array}$ & $\begin{array}{c}\text { Compliant } \\
\text { female } \\
\text { patients } \\
\mathbf{N}(\%)\end{array}$ & $\begin{array}{c}\text { Total } \\
\text { compliant } \\
\text { patients N(\%) }\end{array}$ & $\begin{array}{c}\text { Non- } \\
\text { compliant } \\
\text { male patients } \\
\mathbf{N}(\%)\end{array}$ & $\begin{array}{c}\text { Non-compliant } \\
\text { female } \\
\text { patients N(\%) }\end{array}$ & $\begin{array}{c}\text { Total } \\
\text { non-compliant } \\
\text { patients N(\%) }\end{array}$ \\
\hline None (34) & $10(4.55)$ & $13(5.91)$ & $23(10.45)$ & $25(11.36)$ & $27(12.27)$ & $52(23.64)$ \\
Primary (18) & $2(0.91)$ & $5(2.27)$ & $7(3.18)$ & $16(7.27)$ & $17(7.72)$ & $33(15.00)$ \\
Secondary & $5(2.27)$ & $12(5.45)$ & $17(7.72)$ & $21(9.55)$ & $21(9.55)$ & $42(19.09)$ \\
Tertiary (21) & $5(2.27)$ & $6(2.73)$ & $11(5.00)$ & $16(7.27)$ & $19(8.64)$ & $35(15.91)$ \\
Total (100) & $22(10)$ & $36(16.36)$ & $58(26.36)$ & $78(35.45)$ & $84(38.18)$ & $162(73.64)$ \\
\hline
\end{tabular}

Table 3: Financial status of diabetic patients

\begin{tabular}{lllllll}
\hline $\begin{array}{l}\text { Income } \\
\text { status }\end{array}$ & $\begin{array}{l}\text { Compliant } \\
\text { male } \\
\text { patients N(\%) }\end{array}$ & $\begin{array}{l}\text { Compliant } \\
\text { female } \\
\text { patients N(\%) }\end{array}$ & $\begin{array}{l}\text { Total } \\
\text { compliant } \\
\text { patients N(\%) }\end{array}$ & $\begin{array}{l}\text { Non- } \\
\text { compliant } \\
\text { male patients } \\
\mathbf{N}(\%)\end{array}$ & $\begin{array}{l}\text { Non- } \\
\text { compliant } \\
\text { female } \\
\text { patients N(\%) }\end{array}$ & $\begin{array}{l}\text { Total non- } \\
\text { compliant } \\
\text { patients } \\
\text { N(\%) }\end{array}$ \\
\hline High & $3(1.36)$ & $6(2.73)$ & $9(4.09)$ & $5(2.27)$ & $4(1.82)$ & $9(4.09)$ \\
Medium & $12(5.45)$ & $26(11.82)$ & $38(17.27)$ & $46(20.91)$ & $43(19.55)$ & $89(40.45)$ \\
Low & $7(3.18)$ & $4(1.82)$ & $11(5.00)$ & $27(12.27)$ & $37(16.81)$ & $64(29.09)$ \\
Total & $22(10)$ & $36(16.36)$ & $58(26.36)$ & $78(35.45)$ & $84(38.18)$ & $162(73.64)$ \\
\hline
\end{tabular}

Table 4: Belief in medication efficacy among diabetic patients

\begin{tabular}{|c|c|c|c|c|c|c|}
\hline $\begin{array}{l}\text { Belief } \\
\text { medication } \\
\text { efficacy }\end{array}$ & $\begin{array}{l}\text { Compliant } \\
\text { male } \\
\text { patients } \\
\mathrm{N}(\%)\end{array}$ & $\begin{array}{l}\text { Compliant } \\
\text { female } \\
\text { patients } \\
\mathrm{N}(\%)\end{array}$ & $\begin{array}{l}\text { Total no. of } \\
\text { compliant } \\
\text { patients } \\
\mathrm{N}(\%)\end{array}$ & $\begin{array}{l}\text { Non- } \\
\text { compliant } \\
\text { male } \\
\text { patients } \\
\mathrm{N}(\%)\end{array}$ & $\begin{array}{l}\text { Non- } \\
\text { compliant } \\
\text { female } \\
\text { patients } \\
\mathrm{N}(\%)\end{array}$ & $\begin{array}{l}\text { Total no. } \\
\text { non- } \\
\text { compliant } \\
\text { patients } \\
\mathrm{N}(\%)\end{array}$ \\
\hline Yes & $16(7.27)$ & $18(8.18)$ & $34(15.46)$ & $37(16.82)$ & $56(25.46)$ & $93(42.27)$ \\
\hline No & $6(2.73)$ & $18(8.18)$ & 24 (10.91) & 41 (18.63) & 28 (12.72) & 69 (31.36) \\
\hline Total $(100 \%)$ & $22(10)^{\prime}$ & $36(16.36)$ & $58(26.36)$ & 78 (35.45) & $84(38.18)$ & $162(73.64)$ \\
\hline
\end{tabular}




\section{DISCUSSION}

Teaching Hospital over a period of 16 weeks. We established non-compliance, identified factors that could lead to non-compliance and suggested possible ways to reducing this problem.

The study showed that 58 patients $(26.36 \%)$ were compliant with their medication regimens, while 162 patients $(73.64 \%)$ were noncompliant. The above statement supports the assertion of Urquhart that about one-third or more of patients have poor compliance with prescribed medications irrespective of disease [8].

About $62 \%$ of patients on anti-diabetic therapy discontinue treatment within one year while some use their medications irregularly [5]. Electronic monitoring methods that have been used to measure compliance also reveal that greater than $30 \%$ of patients omit many prescribed doses, irrespective of disease, symptoms or prognosis [8].

Forgetfulness was the most common reason for non-compliance among the diabetic patients used in the study. From the result, about 95 patients $(43.18 \%)$ admitted to skipping doses of their medications at one time or the other. This includes patients on glibenclamide and metformin alone and also those patients on insulin. If patients have a hectic lifestyle or irregular schedule, these also pose a risk that patients will forget to take their medications [9].

The results of our study showed that there is a significant association $(p<0.05)$ between patients' income status and compliance with prescribed medications. The cost of drugs is obstacle to compliance with most patients irrespective of diseases. A patient experiencing financial constraint may find it difficult to spend money on drug particularly if immediate change in health conditions is not evident [10]. Butler et al found that lack of compliance may be related to perceived financial distress by the patient rather than an actual cost of the medications or the source of payment.

The side effects of drugs seem to be another reason though there was no significant relationship $(p>0.05)$ between side effects and compliance. The fears of hypoglycemia and weight gain are other factors that can adversely influence patients' ability to adhere to treatment [7]. Whereas hypoglycemia is less common among patients with Type 2 diabetes mellitus compared to those with Type 1, its fear may inhibit both physicians and patients from optimizing care [11]. From the study, it was gathered that diabetic patients on insulin, whether prescribed alone or in combination with glibenclamide or metformin or both had their compliance affected because of constant injection of insulin which they claimed can be quite tasking day in day out. The patients gave some side effects which included nausea, gastrointestinal disturbances, mild headache, etc as some reasons that might have affected their compliance with their medication. Adherence to medications appears to decrease with perceived and real side effects and patients need to be counseled to maintain compliance.

There was no significant association $(p>0.05)$ between patients' belief of efficacy of prescribed medication and compliance. The vast majority of diabetic patients self-administer their own medications, as such patients' attitude and beliefs can strongly influence their compliance; though from this study it seems most patients still comply poorly even with the belief that the medications are efficient. This finding is supported by that of Urquhart who showed that provision of information on the drugs and their efficacy does little to ensure that doses are taken regularly and on time [8].

Attitudinal barriers to non-compliance represent intrinsic beliefs held by the patients that have been shaped by psychological and social factors unique to these individual. Attitude interacting with social, psychology, economic and structural factors influence patients' behavior and determine compliance [10].

No significant association was seen between the number of prescribed medication and patients' compliance. This does not however conform to most other studies as adherence to medication regimen appears to decrease with an increasing number of drugs and number of doses per day [10]. In this study, those patients placed on a combination of two of the anti-diabetic drugs (insulin, glibenclamide and metformin) formed the largest number of non-compliant patients. With every additional medication, a patient must take each with its own dosing instructions thus the potential for error becomes greater. Likewise, the more complex the regimen, the worse the compliance will be. Thus if all medicines are to be taken at the same time of day, compliance will be higher than of several different time throughout the day are used $[10,12]$. 
Although one might expect that the number of patients placed on three drugs (insulin, glibenclamide and metformin), would have the highest number of non-compliant patients, compared to patients on one or two anti-diabetic medication but this, however, may not always be the case as a patient on two or more drugs takes them once a day at the same time and therefore may be more compliant than a patient on one drug who takes it three times daily.

\section{CONCLUSION}

It is clear that medication adherence is a complex behavior and hence development of effective intervention can improve compliance only when mechanisms underlying the behaviors are better understood. It is recommended that patients should be educated on the importance of complying with prescribed drug regimen, and that physicians should prescribe the drug regimen least likely to result in adverse effects and monitoring for achievement of normal blood glucose level.

\section{Limitations of the study}

A major limitation of our study was the tool used in the collection of the data (questionnaire). This method relied on asking patients about their compliance and no objective method of observation whatsoever was involved. There can also be a tendency for patients to exaggerate their compliance and also for some patients to deliberately indicate a poor level of compliance.

\section{REFERENCES}

1. Eraker SA, Kirsht JP, Becker MH. Understanding and improving patients' compliance. Ann Med 1984; 100: 258-268.

2. International Diabetes Federation (IDF). Diabetes Atlas 2nd edn.2003.

3. Sarah W, Gojka R, Anders G, Richard S, Hilary K. Global prevalence of diabetes (estimates for the year 2000 and projections for 2030). Diabetes Care 2004; 27 : 1047-1053.

4. Lutfey KE, Wishner W. Beyond "compliance is "adherence" Improving the prospect of diabetes care. Diabetes Care 1999; 22: 635-639.

5. Jayan $D$, Lawrence $B$, and Richard GJ. Feature article on factors influencing parents acceptability of diabetic treatment regimen. Clin Diabetes 2000; 18 (2) 1-9.

6. Blaum CS, Velez L, Hiss RG, Halter JB. Characteristics related to poor glycaemic control in NIDDM patients in community practice. Diabetes Care 1997; 20: 7-11.

7. Thompson CJ, Cunnings JF, Chalmers J, Gould C, Newton RW. How have patients reacted to the implications of the DCCT? Diabetes Care 1996; 19: 876-879.

8. Urquhart J. Patient non-compliance with drugs regimens. Measurement, clinical correlates. Economic Impact in Eur J Heart 1996; 17: 8-15.

9. Index of Essential Medicines 2002-2003, World Health Organization, Geneva pp 149-176.

10. Counseling to enhance compliance, Pharmacist-patientconsultation programme, PPCP-unit 3, Pfizer Inc, UK.

11. Korzon-Burakowska A, Hopkins D, Matyka K, Lomas J, Pernet A, Macdonald I, Amiel S. Effects of glycaemic control on protective response against hypoglycemia in Type 2 diabetes, Diabetic Care 1998; 21: 283-290.

12. Winfield J, Richards R. Compliance in Pharmaceutical Practice. Churchill Livingstone; 1999; $p 444$. 